\title{
Long-term therapy in COPD: any evidence of adverse effect on bone?
}

This article was published in the following Dove Press journal:

International Journal of COPD

30 September 2009

Number of times this article has been viewed

\author{
Arnulf Langhammer \\ Siri Forsmo ${ }^{2}$ \\ Unni Syversen 3,4 \\ 'HUNT Research Centre, \\ Department of Public Health \\ and General Practice, Norwegian \\ University of Science and Technology \\ (NTNU), Verdal, Norway; ${ }^{2}$ Department \\ of Public Health and General \\ Practice, NTNU, Trondheim, Norway; \\ ${ }^{3}$ Department of Cancer Research \\ and Molecular Medicine, NTNU, \\ Trondheim, Norway; ${ }^{4}$ Department \\ of Endocrinology, St. Olav's University \\ Hospital, Trondheim, Norway
}

\begin{abstract}
Patients with COPD have high risk for osteoporosis and fractures. Hip and vertebral fractures might impair mobility, and vertebral fractures further reduce lung function. This review discusses the evidence of bone loss due to medical treatment opposed to disease severity and risk factors for COPD, and therapeutic options for the prevention and treatment of osteoporosis in these patients. A review of the English-language literature was conducted using the MEDLINE database until June 2009. Currently used bronchodilators probably lack adverse effect on bone. Oral corticosteroids (OCS) increase bone resorption and decrease bone formation in a dose response relationship, but the fracture risk is increased more than reflected by bone densitometry. Inhaled corticosteroids (ICS) have been associated with both increased bone loss and fracture risk. This might be a result of confounding by disease severity, but high doses of ICS have similar effects as equipotent doses of OCS. The life-style factors should be modified, use of regular OCS avoided and use of ICS restricted to those with evidenced effect and probably kept at moderate doses. The health care should actively reveal risk factors, include bone densitometry in fracture risk evaluation, and give adequate prevention and treatment for osteoporosis.
\end{abstract}

Keywords: COPD, corticosteroids, bronchodilators, bone mineral density, osteoporosis, fractures

\section{Introduction}

Chronic obstructive pulmonary disease (COPD) is, and will increasingly be, a major cause of morbidity and mortality worldwide. ${ }^{1}$ COPD develops as a consequence of genetic susceptibility, increasing life span, environment and life-style factors. Aging of the population, shared risk factors, especially tobacco smoking, systemic effects by the disease and side effects of treatment contribute to the fact that COPD patients often have many co-morbidities. ${ }^{2-4}$ among these osteoporosis and increased fracture risk.

Patients with moderate to severe COPD have limitations in physical activity, and fractures inevitably could be a heavy additional burden to their dyspnea. Among the oldest, the often disabling consequences of hip fractures frequently initiate the patients' need for home care, transfer to nursery homes and shortening of life. Vertebral fractures influence the mobility of the patients, are associated with back pain, and may also increase dyspnea, as increased thoracic kyphosis and decreased rib mobility add a restrictive component to their lung disease, ${ }^{5,6}$ Hence, effort should be given to secure as good "bone health" as possible in this group of patients.

The aims of this paper are to discuss the potential and observed adverse effect on bone by the medical treatment given to COPD patients, and also discuss to some extent,
Correspondence: Arnulf Langhammer HUNT Research Centre, Dept of Public Health and General Practice, NTNU, N-7650 Verdal, Norway

Tel +4774075180

Fax +4774075181

Email arnulf.langhammer@ntnu.no 
the contribution by the disease itself, life-style factors and co-morbidities. Further, preventive and treatment strategies for osteoporosis are discussed.

\section{Methods}

A MEDLINE literature search for English language papers published until June 2009 was conducted using relevant key terms, in addition to examination of reference lists from pivotal studies and reviews.

\section{Medical treatment of COPD}

According to the Global initiative for chronic Obstructive Lung Disease's guidelines (GOLD), www.goldcopd.com, bronchodilator medications are the main symptomatic treatment of COPD and these include short and long-acting $\beta 2$-agonists and anticholinergics. They increase exercise capacity and health status, whilst long-acting anticholinergics additionally reduce the rate of COPD exacerbations and improve the effectiveness of pulmonary rehabilitation. Theophylline also is effective in COPD, but due to its potential toxicity inhaled bronchodilators are preferred. ${ }^{1}$

Inhaled corticosteroids (ICS) are recommended for severe COPD patients with repeated exacerbations, as they have been shown to reduce the frequency of exacerbations and thus improve health status. ICS combined with a long-acting $\beta 2$-agonist (LABA) are more effective than the individual components. ${ }^{1}$ A recent network meta-analysis by Puhan and coworkers concluded that for mild to moderate COPD, single treatment with LABA or long-acting anticholinergics was the treatment of choice both for symptom control and exacerbation prevention, but for those with $\mathrm{FEV}_{1}<40 \%$ predicted, long-acting anticholinergics was as effective as combination treatment in reducing exacerbations. ${ }^{7}$

Oral corticosteroids (OCS) are recommended for 7 to 10 days with 30 to $40 \mathrm{mg}$ prednisolone in exacerbations in patients with severe COPD, but chronic treatment with OCS should be avoided. ${ }^{1}$

\section{Osteoporosis}

\section{Bone}

The skeleton is essential for terrestrial animal life, and human beings have evolved bone light enough to enable rapid mobility and strong enough to avoid disabling fractures during reproductive life. ${ }^{8}$

Bone mass reaches the peak at age 25 to 30 years. ${ }^{9}$ After a plateau phase, bone loss occurs throughout life with an age-associated annual bone loss of approximately $0.5 \%$ to $1 \%$, but the rate of loss differs by sex, skeletal sites and age.
In men, there is a rather constant bone loss from age 25 to 39 years, this increases mainly at the hips at age $\geq 65$ years, ${ }^{10}$ with further loss of cortical bone above the age of 75 years. ${ }^{11}$ In women, bone loss begins at age 40 to 44 , and is particularly rapid in the total hip at age 50 to 54 with a change of $-6.8 \%$ over 5 years, with another acceleration in loss after age of 70 years. $^{10,11}$

\section{Prevalence of osteoporosis}

Osteoporosis is the main risk factor for fragility fractures, defined as a fracture occurring after a fall from standing height or minor trauma. The lifetime risk of any fracture at age 50 years is about $50 \%$ among women and $20 \%$ among men. ${ }^{12}$ Men at age 75 years have equivalent fracture risk as women aged 65 years. ${ }^{13}$

Osteoporosis is defined as a skeletal disorder characterized by compromised bone strength predisposing a person to an increased risk for fracture. Bone strength primarily reflects the integration of bone density and bone quality. ${ }^{14}$ An operational definition of osteoporosis, established by The World Health Organization (WHO), is based on bone mineral density (BMD). ${ }^{15}$ Bone densitometry results are given as area density, but also as T-scores (standard deviations [SD] compared with young adult sex-matched controls) and Z-scores (compared with age-and sex matched controls). The WHO has defined osteopenia as BMD T-score -1 to $-2.5 \mathrm{SD}$ and osteoporosis as T-score below $-2.5 \mathrm{SD} .{ }^{15}$

\section{Measures of BMD, bone quality and bone metabolism}

Dual energy absorptiometry (DXA) at the hip is the best predictor of hip fractures and best standardized for the diagnosis of osteoporosis. Spine and hip BMD have similar value for predicting spine fractures, ${ }^{16}$ but spondylarthrosis and minerals in the aorta might give artificially high values of BMD in the anterior-posterior directed measurements after the age of 60 to $65 .^{17}$

BMD at these sites are widely used in clinical practice to identify those at increased risk for fracture. However, a majority of fragility fractures occurs in women not being defined as osteoporotic. ${ }^{18}$ The prediction of fractures in both genders improves if baseline BMD is replaced with change in BMD between measurements in the models. ${ }^{19}$ Most clinicians, however, have to rely on one measurement estimating the patients fracture risk. Compared to other risk factors, BMD is at least as good in prediction of fracture as blood pressure measurements to predict stroke and level of cholesterol to predict cardiac infarction. ${ }^{20}$ 
T-scores between different sites should not be compared, due to site differences regarding accuracy errors, variance in the population and algorithms for edge detections..$^{21}$ In a study of the same population of a DTX-base, the prevalence of osteoporosis in women aged 50 years or more, ranged from $11 \%$ at the hip, $24 \%$ at the spine, to $52 \%$ at the distal radius. ${ }^{22}$

Mainly for research purposes, methods like Single X-ray Absorptiometry (SXA), Quantitative Ultrasound (QUS) and Quantitative Computed Tomography (QCT) have been used. Although measurement at a specific site is the best predictor of fracture at that site, forearm SXA is as good as lumbar BMD for prediction of hip fracture, ${ }^{23,24}$ other non-spine fractures ${ }^{25}$ and fragility fractures in general. ${ }^{26}$ Correspondingly, quantitative ultrasound (QUS) of calcaneus has been used to estimate regional BMD-levels, evaluate bone quality ${ }^{27}$ and predict fracture risk, ${ }^{28,29}$ but this method has poor sensitivity for detecting osteoporosis defined as T-score $<-2.5$ SD. ${ }^{30}$

Markers of bone turnover, as alkaline phosphatase, hydroxyproline, osteocalcin, pro-collagen peptides and pyridinium crosslinks, can enhance the predictive value of BMD. ${ }^{20}$ However, due to large biological variability, they are of uncertain clinical relevance and have not been shown to predict the risk of fracture ${ }^{31,32}$ or to correlate with changes in BMD..$^{33}$ They might, however, reflect changes related to antiresorptive therapy more rapidly than changes in BMD. ${ }^{34}$ In general, corticosteroid (CS) administration is followed by a reduction in bone formation markers, especially serum osteocalcin levels, ${ }^{35-37}$ and a trend to an increase or no change in bone resorption markers..$^{38}$

\section{Risk factors for osteoporosis and fracture in COPD}

High age and female sex are important risk factors for osteoporosis, with postmenopausal loss of ovarian hormones being the single most important factor. The prevalence of osteoporosis and incidence of fragility fractures differ substantially between populations, with highest figures in post-menopausal women of Northern European descent, especially those living in Scandinavia. ${ }^{12,39-41}$ Both parental osteoporosis and fragility fractures, as well as previous fracture in the patient, are risk factors for further fracture. ${ }^{42}$

Patients with COPD are at high risk for osteoporosis and fractures because of lifestyle factors, systemic effects of the disease, treatment and comorbidities (Figure 1). Smoking is associated with low BMD in a dose-response relationship,

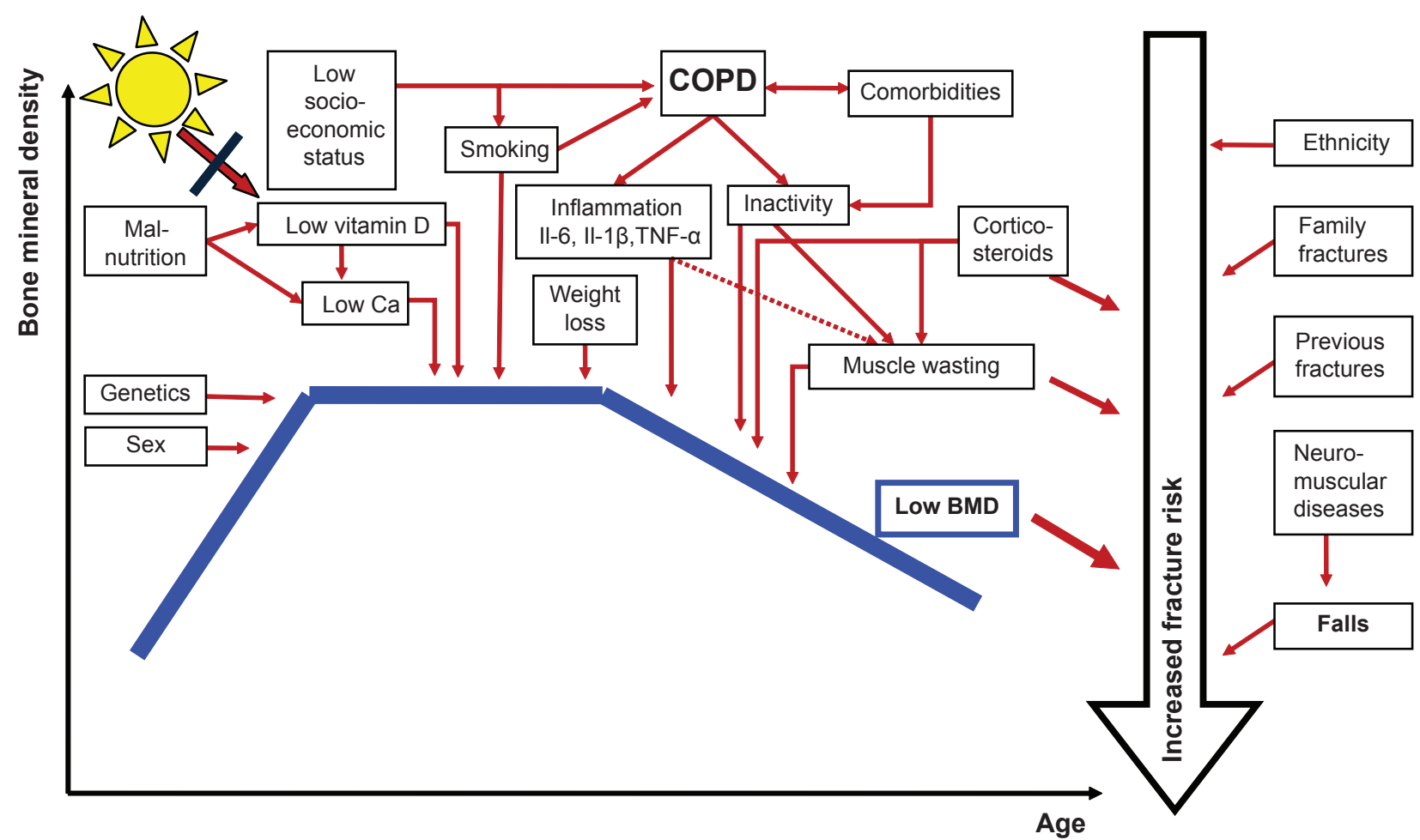

Figure I The development of bone mineral density (BMD) throughout life, factors of importance for level of BMD (genetics, sex), COPD-related factors lowering (BMD), and important factors influencing fracture risk in addition to level of BMD.

Abbreviations: IL, interleukin;TNF- $\alpha$, tumor necrosis factor alpha. 
not only in current smokers, but even ex-smokers. ${ }^{43,44}$ Female lungs seem to be more susceptible to harmful effects of tobacco smoking than male lungs. ${ }^{45,46}$ Increased prevalence of smoke related lung diseases in women and increasing proportion of women among smokers, might affect bone more negatively in women than men, through combined effects of COPD and smoking.

Furthermore, inactivity is an important risk factor for osteoporosis and fractures, partly due to increased risk for falling. A physically active life has been found to nearly halve the incidence of hip fractures in the older population, ${ }^{47}$ and appendicular lean mass accounts for most of the explained variance among factors being positively associated with BMD. ${ }^{41}$

COPD patients, as well as patients with other chronic diseases, often have deficient calcium $(\mathrm{Ca})$ and vitamin $\mathrm{D}$ nutritional status, ${ }^{48,49}$ and the latter is frequently accentuated because of little exposure to sunlight. Weight loss is also associated with decreased $\mathrm{BMD}^{50-52}$ and a recent review reported $\mathrm{BMD}$ to be $3 \%$ to $7 \%$ higher for every $10 \mathrm{~kg}$ increase in weight. ${ }^{43}$ Correspondingly, a recent study found that $\geq 5 \%$ weight loss was associated with a $33 \%$ increased risk of forearm fractures. ${ }^{53}$

In the recent years, a detrimental effect on bone also caused by COPD itself has been suggested. ${ }^{3,54}$ Among many possible explanations, most current evidence indicates that this is a result of mediators, cytokines (interleukin [I1]-6, Il-1 $\beta$ and TNF- $\alpha$ ) or activated inflammatory cells reaching the systemic circulation from inflammation in the lungs. ${ }^{3,4}$ The extent of this contribution is unclear, but the fact that patients on OCS have higher risk of fractures compared to untreated patients with similar underlying inflammatory diseases $^{55}$ indicates that this is not one of the main causes of the influence on bone.

\section{Medicine-induced osteoporosis in COPD}

Many studies have addressed this subject, but the main problem or limitation of many of these studies are the power to reveal any effect, and, in case of effect, to differentiate between possible effects by medication, disease severity and factors mentioned above. There have been a few large, randomized, double-blind, clinical trials (RCT), many observational case-control and cohort studies, in addition to many meta-analyses. Some larger and important studies are based on registers as the UK General Practice Research Database (GPRD) (190,000 to 240,000 cases using CS). ${ }^{56,57}$ and Danish data based on the National Hospital Discharge Register and others $(>125,000$ fracture cases $) .{ }^{58}$

\section{How can adverse effects on bone be measured?}

Outcomes such as fractures, or surrogate measures of fracture risk, as BMD and biochemical markers for bone turnover, might be relevant for studies on adverse effects on bone. RCT including fractures as primary outcome would give the best evidence of such an effect. However, even as lifetime fracture risk is high, only a small number of subjects at risk actually sustain a fracture during few years observation time. For example, in any year, fractures occur in 1 to 2 per 100 women aged 65 years, 6 to 10 per 100 women aged 75 years, and only 1 to 2 per 2,000 of the $15 \%$ of women $<60$ years of age with osteoporosis. ${ }^{59}$ Even for BMD, there are problems with the power of studies. Wisniewski et al calculated that a prospective study comparing a dose of $1 \mathrm{mg}$ beclomethasone dipropionate (BDP) equivalents with placebo, would require 2,500 individuals in each limb for $95 \%$ power to detect the difference of 0.1 SD in BMD found in their cross-sectional study. ${ }^{60}$

\section{Airway obstruction, COPD and bone}

Airflow obstruction is associated with increased risk of osteoporosis compared with normal lung function. ${ }^{61,62} \mathrm{COPD}$ is an independent predictor of BMD reduction ${ }^{63-65}$ and vertebral fracture risk. ${ }^{66}$ Studies have shown more than two-fold prevalence of osteoporosis in CS-naïve COPD patients, compared both with healthy controls ${ }^{67}$ and asthma patients. ${ }^{68}$ Increasing disease severity increases the risk for osteoporosis, ${ }^{29,61,69}$ and in severe COPD osteoporosis and osteopenia have been found in as many as $66 \%$ and $31 \%$, respectively. ${ }^{70}$

Correspondingly, the fracture risk is positively associated with COPD severity. ${ }^{71}$ In mild COPD the fracture risk is similar to what was found in the European Vertebral Osteoporosis Study (EVOS), ${ }^{72}$ with a prevalence of vertebral deformity of $12 \%$ in both genders aged 50 to 79 years, ${ }^{73}$ but more COPD patients than healthy, had at least 1 severe vertebral fracture $(\mathrm{OR}=3.75) .{ }^{6}$ Nuti et al reported at least 1 vertebral fractures in about $40 \%$ of COPD patients, with a strong association between disease severity and fractures, especially in men, ${ }^{71}$ and in a recent Norwegian study, the number of vertebral deformities was almost twice as high in GOLD stage III compared to II in women. ${ }^{74}$ In the large Danish register study, comparing subjects with and without COPD, COPD adjusted for use of CS was associated with increased risk for hip and vertebral fracture (relative risk [RR] 1.63 and 1.23), but not for forearm fractures. Comparing those with and without asthma, revealed an asthma-related increased risk for only hip fracture (RR 1.32). ${ }^{58}$ 
Vertebral compression fractures often are asymptomatic, and among severe COPD patients, not previously diagnosed compression fractures were found in $24 \%{ }^{75}$ A prospective study revealed that compared to subjects without COPD, incident COPD patients had increased risk for osteoporosis and fracture (RR 3.1 and 1.6, respectively) within the first year after diagnosis. ${ }^{2}$

\section{Treatment of COPD and effect on bone \\ Oral glucocorticoids}

A GPRD study documented that women aged $\geq 85$ years using $\geq 7.5 \mathrm{mg}$ prednisolone daily had an excess in number of hip fracture cases of 1.4 cases per 100 patients per year compared to non-users, and as many as $47 \%$ and $72 \%$ of all hip and vertebral fractures, respectively, could be attributed to OCS. ${ }^{76}$ Walsh et al found that patients on OCS for $\geq 6$ months compared to controls had increased risk of osteoporotic fractures of the vertebrae (OR 10), hip (OR 6), and ribs or sternum (OR 3.2)..$^{77}$

In a comprehensive meta-analysis van Staa et al found strong correlations between cumulative dose and bone loss and between daily dose ( $>5 \mathrm{mg}$ prednisolone) and risk of fracture. The fracture risk increased within 3 to 6 months after the start of OCS, and decreased after stopping therapy. The increased risk remained independent of underlying disease, age and gender ${ }^{78}$ Later, van Staa ${ }^{79}$ reviewed several large population based studies on fracture risk in CS users, and found consistent increased fracture risk in CS users in the hip (RR 1.61 to 2.01) and spine (RR 2.60 to 4.16). Only one study from the GPRD showed a minor increased risk for forearm fractures compared to controls (RR 1.09). ${ }^{57}$ In a study by Angeli et al including 551 post-menopausal women given CS for different diseases, the adjusted prevalence of asymptomatic vertebral fractures was $38 \%$ for asthma/COPD.
No significant association, however, was found between fractures and CS cumulative dose or duration of therapy. ${ }^{80}$

These studies confirm that the vertebral bodies are affected earlier and more severely than cortical bone of the long bones (radius, humerus) during OCS treatment. ${ }^{81}$ Different patterns of loss have also been demonstrated within the lumbar spine with greater damage to the trabecular bone than the cortical bone of the spinosi and apophyseal area ${ }^{82}$

\section{Dose response relationship}

There have been discussions on a threshold dose above which oral CS cause bone loss. The two large register-based studies both found increased risk for hip and vertebral fractures in a dose response relationship above daily doses as low as $2.5 \mathrm{mg}$ prednisone equivalents, ${ }^{57,58}$ and similar results have later been demonstrated by de Vries et al ${ }^{56}$ (Table 1). In line with this, Li et al found that COPD patients with a fracture history, reported treatment with higher doses of prednisone compared to those without fractures. ${ }^{70}$

However, opposed to this, recent analyses of the Danish register $^{83}$ and the Dutch PHARMO-RLS database ${ }^{84}$ did not find any increase in overall fracture risk for prednisolone doses $<7.5 \mathrm{mg}$ per day. This could be a result of less residual confounding due to adjustments for proxies for disease severity and other risk factors for fractures. A limitation of register-based studies, is lack of individual life style data, but inclusion of such data rather should weaken the association between CS use and fracture.

Increased fracture risk by duration of OCS use has been found in studies on patients with rheumatoid arthritis and lupus, ${ }^{85-87}$ and both Walsh ${ }^{77}$ and de Vries ${ }^{56}$ with coworkers have reported a substantial increased risk for fractures with increasing cumulative dose of CS. Walsh found that the highest compared to lowest cumulative quartile (median prednisolone dose $61 \mathrm{~g}$ versus $5 \mathrm{~g}$ ) had an increased risk ranging from 2 for all fractures to 9 for vertebral fractures. ${ }^{77}$

Table I Adjusted odds ratio for fracture risk at different sites by daily dose of prednisolone in UK General Practice Research Database (GPRD) and Danish large register studies

\begin{tabular}{|c|c|c|c|c|c|c|c|}
\hline \multirow{2}{*}{$\begin{array}{l}\text { Prednisolone } \\
\text { daily dose }\end{array}$} & \multicolumn{3}{|c|}{ Danish register study Vestergaard et al ${ }^{58}$} & \multicolumn{2}{|c|}{ GPRD study Van Staa ${ }^{57}$} & \multicolumn{2}{|c|}{ GPRD study de Vries et $a^{56}$} \\
\hline & Forearm & Hip & Spine & Hip & Spine & Hip/femur & Spine \\
\hline$<2.5 \mathrm{mg}$ & $0.99(0.89-1.09)$ & $0.97(0.87-1.08)$ & $\mathrm{I} .16(0.95-1.4 \mathrm{I})$ & $0.99(0.82-1.20)$ & $1.55(1.20-2.01)$ & \multirow{2}{*}{$1.40(1.24-1.57)$} & \multirow{2}{*}{$2.89(2.47-3.39)$} \\
\hline $2.5-7.49 \mathrm{mg}$ & $1.14(0.98-1.33)$ & $1.27(1.11-1.44)$ & $1.54(1.18-1.99)$ & $1.77(1.55-2.02)$ & $2.59(2.16-3.10)$ & & \\
\hline$>7.5 \mathrm{mg}$ & $1.19(0.99-1.43)$ & $1.45(1.25-1.69)$ & $2.08(1.54-2.79)$ & $2.27(1.94-2.66)$ & $5.18(4.25-6.31)$ & $2.17(1.87-2.5 I)$ & $4.00(3.29-4.86)$ \\
\hline
\end{tabular}

Notes: The Danish study comprised 124,655 subjects having sustained a fracture during the year 2000 compared to matched controls. ${ }^{58}$ The GPRD study by van Staa comprised 244,235 oral corticosteroid (OCS) users compared to matched controls aged $\geq 18$ years. Respiratory disease accounted for $40 \%$ of treatment indications. ${ }^{57}$ The GPRD-study by de Vries comprised 191,752 subjects aged $\geq 40$ years who received OCS compared to past users of CS. ${ }^{56}$ 
Results from two RCTs, however, indicated that not the cumulative, but the daily CS dose was a strong predictor for vertebral fracture, with $60 \%$ increase in risk for each $10 \mathrm{mg}$ increase in prednisolone dose. ${ }^{88}$ Based on an administrative US database, Steinbuch et al reported dose response relationship for both duration and dose of OCS. Long and continuous use of CS resulted in a significant 5-fold increased risk of hip and 6 fold increased risk of vertebral fractures. Adding high doses of prednisolone to this, the RR increased to 7-fold for hip and 17-fold for vertebral fractures. ${ }^{89}$

CS related bone loss is most rapid during the first 6 months of OCS treatment (on average 5\%), after which there seems to be a slower but steady loss of bone ( $1 \%$ to $2 \%$ per year). ${ }^{90,91}$

An increased risk for fractures has been shown for doses above $5 \mathrm{mg}$ /day within 3 to 6 months after initiation of OCS therapy, ${ }^{78,89}$ and for doses of $\geq 10 \mathrm{mg}$ prednisolone for less than 60 days with an increasing trend by time. ${ }^{83}$ Vestergaard and coworkers also found an effect of lower doses within 60 days, but this effect did not last beyond 2 months, and was probably an effect of confounding by indication. Correspondingly, van Staa found increased fracture risk even before OCS was initiated. ${ }^{57}$

Avoidance of continuous use has been believed to reduce adverse effects on bone. ${ }^{92}$ Alternate, in stead of daily use of OCS has not been found to reduce bone loss in adults. ${ }^{93,94}$ However, long-time sporadic use has been reported to be associated with a 2-fold increased fracture risk, compared to a 6-fold increased fracture risk in those with continuous use of OCS $^{89}$. In a GPRD study, patients with previous cumulative dose CS $\leq 1 \mathrm{~g}$ with intermittent high-dose CS (daily dose $\geq 15 \mathrm{mg}$ ) only had a small increased risk, whilst those with a daily dose $\geq 30 \mathrm{mg}$ and cumulative exposure $>5 \mathrm{~g}$ had a relative risk of hip/femur and vertebral fracture of 3.13 and 14.42 , respectively. ${ }^{56}$

Treatment of exacerbations is an important exposure for OCS in COPD patients. Dubois et al showed that OCS courses were associated with more harmful effects against bone compared to continuous OCS treatment regimens (>10 mg prednisolone/day). ${ }^{95}$ The study indicated alarming bone loss of a cumulative dose above $1 \mathrm{~g}$ of prednisolone equal to 2 to 3 OCS courses. Corresponding effect on lumbar $\mathrm{BMD}$ has been reported in asthma patients receiving more than 2.5 courses of OCS compared to fewer. ${ }^{96}$

\section{Reversible effect}

Regaining of BMD to normal levels was found in the 1990s in patients cured for Cushing disease ${ }^{97}$ and patients having stopped OCS therapy. ${ }^{87,98}$ Newer register studies showed that the increased risk of fracture in OCS-users mostly disappeared within one year after stopping therapy, most pronounced for vertebral fractures, but even the risk for hip fractures was reduced towards baseline levels. ${ }^{57,58,83}$ There is a rapid decrease in fracture risk beginning already three months after stopping CS treatment, ${ }^{56}$ but the time for fracture risk to return to normal, depend on the cumulative dose used, from 6 months after cumulative dose of less than $1 \mathrm{~g}$ prednisolone to at least 15 months at higher cumulative dose and daily dose above $15 \mathrm{mg} .{ }^{56}$ However, at cumulative doses $>10 \mathrm{~g}$ there is both a thinning and perforation of the trabeculae of such an extent that bone recovery is precluded after withdrawal of CS. ${ }^{99}$

\section{OCS and BMD}

Due to disruption of collagen structure and bone architecture, rather than demineralization by CS treatment, ${ }^{100,101}$ the increased fracture risk in OCS users seems to be mostly independent of BMD. This explains why adjustments for BMD have not changed substantially the relative fracture rate in OCS, ${ }^{102}$ and why CS users compared to non-users have higher risk for vertebral fractures at the same levels of BMD. ${ }^{88}$

However, bone loss due to OCS can be measured by BMD. This was first found after short time use in patients with rheumatoid arthritis and chronic fatigue syndrome; ${ }^{98,103}$ a mean daily dose of $7.5 \mathrm{mg}$ prednisolone for 20 weeks led to $9 \%$ increased loss in trabecular bone compared to placebo. ${ }^{98}$ Corresponding effects of OCS on BMD are found in COPD patients.

\section{ICS and bone}

Medication for inhalation was developed in order to ensure high deposition in the airways with lowest possible systemic side effects. Even though the gastrointestinal absorption of ICS like budesonide (BUD) and fluticasone (FLU) is very low compared to BDP and triamcinolone (TCA), ${ }^{104}$ the active medication deposited in the airway, will reach the systemic circulation. Adverse effects on bone could be possible, and reviewers have found reason to concern about this. ${ }^{105,106}$

\section{ICS and fractures}

\section{Randomized controlled trials (RCT)}

As part of a systematic review and meta-analysis of RCT, Drummond et al included three larger studies on ICS with fractures as secondary outcome. ${ }^{107}$ The studies compared combined salmeterol (SAL)/fluticasone (FLU) with each 
components alone and placebo for a period of 3 years in 6,112 COPD patients, ${ }^{36}$ FLU with placebo in 751 patients with moderate to severe COPD, ${ }^{108}$ and BUD with placebo in 1,277 smokers with mild COPD for 3 years. ${ }^{73}$ Despite use of rather high doses (FLU $500 \mu \mathrm{g}$ twice daily and BUD $400 \mu \mathrm{g}$ twice daily), no difference in fracture risk was found between the treatment groups. A Cochrane review of seven RCT found no effects of 2 to 3 years use of conventional doses of ICS on BMD or fracture risk, but very high doses were associated with increase in markers of bone turnover. ${ }^{31}$ Altogether the studies included cases with mild to severe COPD, doses considered as moderate to high, but the follow-up time was short compared to what is the case for most COPD patients.

\section{Observational studies}

Knowledge on potential effects of ICS on bone could be derived from studies including asthma patients, as these lack many of the negative life-style factors characteristic of COPD patients. Lipworth et al in 2002 reviewed available literature on ICS and systemic adverse effects published from 1966 through 1998, and found that all ICS, but especially FLU (at doses above $800 \mu \mathrm{g}$ ), exhibited dose-related adrenal suppression, a risk factor for bone loss. Data on bone turnover, however, were not included in these studies. ${ }^{109}$

In 2003 Richy et al reviewed all controlled trials having data on ICS, and BMD/markers/fractures in asthma, COPD and healthy persons. ${ }^{110}$ Data from the included studies showed that all considered ICS, compared with placebo or controls, appeared to affect bone markers or lumbar BMD in asthma, COPD or in healthy adults, but the study lacked power to investigate fracture risk. TCA led to the most deleterious effects on bone, followed by BDP and BUD. There was a dose response relationship, both regarding daily dose and duration of ICS use, and bone loss. Assuming a linear bone loss in CS-induced osteoporosis, use of TCA $1 \mathrm{mg}$ /day during 20 years would lead to an estimated $6.7 \%$ decrease in BMD compared with unexposed asthma or COPD controls, whereas corresponding figure for BUD would be $2.4 \%$. However, as the authors discussed, there might be not-linear time-effect model due to compensatory mechanisms in patients exposed to ICS on a long-term basis. Furthermore, two of the studies ${ }^{73,111}$ included specifically smokers, who where older than in the other studies. Excluding these, rendered the results non-significant, suggesting that an effect of aging, smoking and higher cumulative dose of ICS might have influenced the results.

Based on the Danish register, Vestergaard et al found a limited increase in the risk of any fracture, but not hip, spine or forearm fractures, in ICS-users of more than $7.5 \mathrm{mg}$ prednisolone equivalents per day (equivalent to $1875 \mu \mathrm{g}$ of BUD per day). ${ }^{58}$ Van Staa et al based on GPRD data, four years earlier, had reported increased risk for fracture at all these sites, and even in a dose-response relationship effect by ICS. However, they did neither find differences in fracture risk between the ICS and bronchodilator groups compared with non-users, nor between users of different ICS (BUD, FLU and BDP). ${ }^{112}$ Restricting a study to elderly women in the same database, Hubbard et al, found ICS-use to be associated with increased fracture risk (OR 1.19 adjusted for OCS) and in a dose response relationship. ${ }^{113}$ Including disease severity indicators as confounders in a study from the same database, de Vries et al found that the crude two-fold fracture risk at the hip in patients on high dose ICS $(>1.6 \mathrm{mg})$ was reduced to similar risk as non-users of ICS, ${ }^{66}$ and later they found similar result in a Dutch study. ${ }^{84}$

However, even recent studies have reported a small increase in fracture risk by ICS, but mainly with use of higher doses. ${ }^{71,114,115}$

CS have less influence on appendicular bone than hip and spine. Even so, in a cross-sectional population-based study in Norway, current users of only ICS had 2\% lower forearm BMD compared to ICS-naïve individuals, and additional use of OCS was associated with 8\% lower BMD. ${ }^{116}$ Similar results were found during a follow-up study for 5 years, ${ }^{117}$ but despite the possibility to adjust for both diseases severity, other risk factors and individual life style factors, lack of any dose response relationship between ICS-use and BMD, could indicate confounding by disease severity.

The studies do not fully preclude adverse effects of at least high dose ICS on bone, but what is the clinical relevance of such an effect? Weatherall et al addressed this in a recent systematic review and meta-analysis of 5 case-control studies of ICS use. ${ }^{118}$ The random-effects odds ratio of relative risk for a non-vertebral fracture was 1.12 (95\% confidence interval 1.00 to 1.26 ) per $1.0 \mathrm{mg}$ increase in the daily dose of BDP or equivalent. This risk was considerably less than other common risk factors for fracture in the older adult, with figures of: 1 or more falls 4.7, use of antipsychotic medication 2.8 , body mass index $<18.5 \mathrm{~kg} / \mathrm{m}^{2} 2.4$, cerebrovascular disease 1.9 , use of hypnotic medication 1.7 , and being a current smoker 1.5. ${ }^{118}$

\section{What dose level of ICS is used in COPD?} Mild asthma is very responsive to CS, and most of the therapeutic effect of ICS is obtained at doses around 400 to $500 \mu \mathrm{g}$ of BDP equivalents, with the mean dose achieving 
the maximum benefit being around 1,000 $\mu \mathrm{g}$ /day. ${ }^{119,120}$ CS suppress the multiple inflammatory genes that are activated through recruitment of the enzyme histone deacetylase 2 (HDAC2). Smoking, however, contributes to steroid resistance ${ }^{121}$ through negative effect on HDAC2. ${ }^{122}$ Hence, for optimal CS response, COPD patients and smoking asthma patients need higher CS doses compared with nonsmokers. As the introduction of ICS combined with LABA in asthma patients has led to asthma control at lower ICS doses, ${ }^{123}$ the concern for negative effects on bone among these patients are minimized compared to smokers with asthma or COPD. Even though significant differences between single ICS and combination therapy on BMD and bone metabolism markers were not found, a study indicated more favorable pattern for the combination therapy. ${ }^{124}$

RCTs on the effect of ICS on different outcomes in COPD patients have mostly used higher doses of ICS than is generally used in asthma patients. Daily doses of FLU have been $500 \mu \mathrm{g}$ twice daily, ${ }^{36,108,125-128}$ BUD 320 to $400 \mu \mathrm{g}$ twice daily ${ }^{73,129-131}$ and TCA $1,200 \mu \mathrm{g} /$ day. ${ }^{111}$ Recently, however, Ferguson et al published a RCT reporting a similar reduction in annual rate of exacerbation by FLU/SAL $250 / 50 \mu \mathrm{g} / \mathrm{mg}$ twice daily ( $30 \%$ compared with SAL) as reported in previous studies of double ICS dose. ${ }^{132}$ Two other studies of shorter duration (24 weeks) showed that FLU/SAL 250/50 bid improved lung function and reduced severity of dyspnea compared with individual components and placebo, but these had not power to study exacerbations. ${ }^{133,134}$ Further studies on defining the lowest dose needed to reach the desirable effects of ICS are therefore warranted. Today there is a discrepancy between the size of doses used in the majority of studies and doses prescribed in the clinic. In the US, higher doses than FLU/SAL 250/50 and BUD/FOR 320/9 $\mu \mathrm{g} / \mathrm{mg}$ twice daily are currently not approved for use in COPD.

For CS exposure during exacerbations, Stallberg et al in a RCT found no difference between 2 weeks of high-dose BUD/FOR combination and prednisolone $30 \mathrm{mg} .{ }^{135}$ Even if all patients were given one dose of prednisolone 30 to $50 \mathrm{mg}$ before randomization, the total CS exposure in those getting ICS would be about one-third of those receiving OCS.

\section{Bone turnover and influence of inflammation}

In all individuals there is a continuous bone remodeling, and in adults about $25 \%$ of trabecular and $3 \%$ of cortical bone are replaced each year. ${ }^{136}$ Central cells in this balance are osteoclasts, which resorb bone, and osteoblasts, which replace lost bone with new matrix, which subsequently mineralizes. Osteocytes and their canicular network serve as mechanosensors, and play a role in the repair of bone microdamage. ${ }^{137}$ There is a close interaction between osteoblasts and osteoclasts, mainly mediated by receptor activator of NF- $\mathrm{\kappa B}$ ligand (RANKL) and osteoprotegerin (OPG). RANKL is expressed on the surface of osteoblasts, and its expression increases in response to different pro-resorptive signals such as proinflammatory cytokines, CS, estrogen deficiency and excess of parathyroid hormone. ${ }^{138}$ RANKL is the critical stimulator of the differentiation and activity of ostoclasts leading to bone resorption. OPG is a decoy receptor that is secreted by osteoblasts and reduces bone resorption by binding to RANKL. ${ }^{139,140}$

The influence of inflammatory diseases on bone is thoroughly discussed in a recent review by Hardy and Cooper. ${ }^{140}$ Shortly, inflammatory cells also express or secrete RANKL, or produce cytokines (TNF- $\alpha$ and interleukins) promoting bone resorption independent of osteoblasts. ${ }^{141}$ Why increased bone resorption is not followed by bone formation is unclear, but at least TNF- $\alpha$ inhibit the differentiation of osteoblasts. $^{142}$

Interestingly, inflammation modifies the action of the

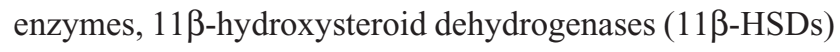
responsible for the intracellular CS metabolism. One of these converts inactive CS such as cortisone and prednisone to their active counterparts cortisol and prednisolone. Exposure to proinflammatory cytokines increases the levels of autocrine generated cortisol in the osteoblasts, leading to decreased bone formation through direct effect on osteoblasts, as well as increased osteoclast activity due to upregulation of RANKL and downregulation of OPG. ${ }^{139,143}$ The $11 \beta$-HSDs might contribute to the individual heterogeneity in the response to CS therapy. A common polymorphism in the efflux transporter P-glycoprotein which is associated with CS sensitivity might also confer susceptibility to CS-induced osteoporosis. ${ }^{144}$

\section{The pathogenesis of CS-induced osteoporosis}

Figure 2 shows the bone cells and mechanisms being involved in CS-induced bone loss. The loss occurs in two phases, a rapid early phase, probably due to excessive bone resorption, and a slower, progressive phase due to impaired bone formation. ${ }^{145,146}$ In the first phase CS increase the expression of RANKL and macrophage colony stimulating factor, while decreasing the expression of OPG in stromal and osteoblastic cells, thereby favoring osteoclast differentiation and bone resorption. ${ }^{139}$ Furthermore, CS decrease the apoptosis of mature osteoclasts leading to a prolonged bone resorption. ${ }^{147}$ 


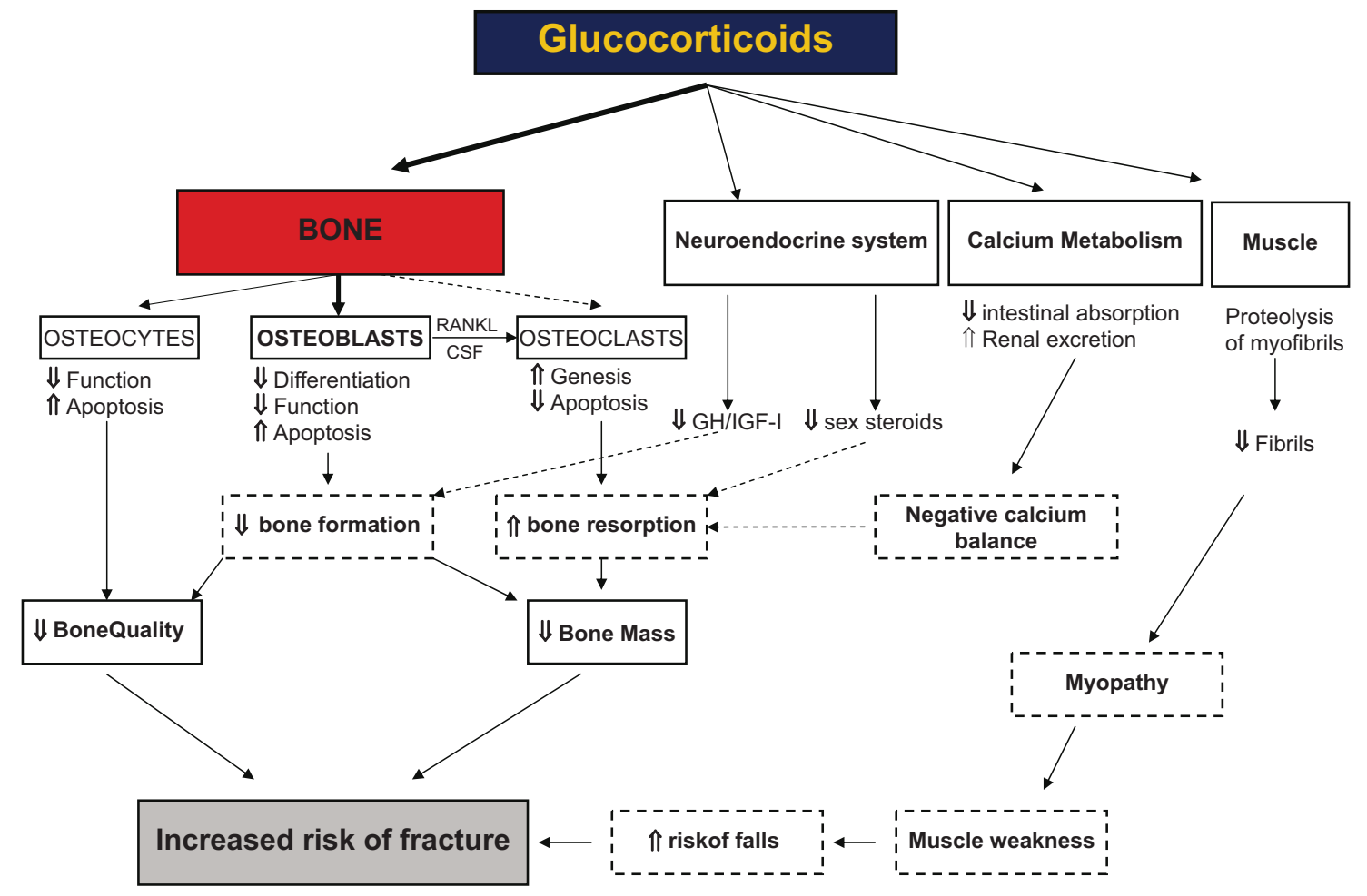

Figure 2 Diagram showing the direct and indirect effects of glucocorticoids on bone leading to glucocorticoid-induced osteoporosis and fractures. Reproduced with permission from Canalis E, Mazziotti G, Giustina A, Bilezikian JP. Glucocorticoid-induced osteoporosis: pathophysiology and therapy. Osteoporos Int. 2007;18(I0):13 I9-1328. ${ }^{49}$ Copyright $\odot 2007$ Taylor \& Francis.

The excess resorption, however, falls with long-term CS, probably due to inhibition of differentiation of osteoclast precursors. ${ }^{147}$

In the second phase, inhibition of proliferation, differentiation as well as maturation of osteoblasts, lead to impairment of bone formation. ${ }^{148,149}$

CS also exert negative effects on osteocytes by disturbing their mechanosensor function and inducing apoptosis. ${ }^{150}$ This reduces the strength of bone, independently of changes in bone remodeling and architecture, ${ }^{151}$ and might partly explain why patients treated with CS experience fractures at a higher BMD level than non-CS users. Additionally, CS have an indirect, negative effect on bone formation by reducing the expression of insulin like growth factor (IGF) $1 .{ }^{145}$ Low levels of gonadal steroids increase bone resorption. ${ }^{152}$ However, even though CS decrease the level of these hormones, the adverse effects are still observed in patients with maintained menstrual cycle activity implying that the adverse effects of CS are largely independent of hypogonadism. ${ }^{153}$

Secondary hyper-parathyroid state, due to the effects of CS as inhibitors of calcium absorption from the gastrointestinal tract and calcium reabsorption in the renal tubuli, has been postulated, but studies have not reported association between CS and increased parathyroid hormone. ${ }^{145}$

Other pathophysiological mechanisms are discussed, among these, redirection of differentiation of bone marrow stromal cells from cells of the osteoblastic lineage to the adipocyte lineage, ${ }^{145}$ and inhibition of osteoblast differentiation by opposing Wnt- $\beta$-catenin signaling. ${ }^{154}$ The relative importance of the various components is not yet known.

CS initially mainly affect trabecular bone due to higher metabolic activity, but with prolonged use cortical bone is also affected. ${ }^{146}$ Muscle weakness and atrophy is also a consequence of OCS treatment. The changes particularly involve the pelvic girdle musculature, with less involvement of the shoulder girdle and distal musculature. It generally occurs within weeks to months after initiation of OCS. In stable patients with COPD, a 2-week course of $30 \mathrm{mg}$ prednisolone was not associated with muscle weakness. ${ }^{155}$

\section{Osteoporosis and fractures associated with other medication \\ Bronchodilators}

Overstimulation of the adrenergic system has been associated with a low BMD or increased bone fragility, ${ }^{156}$ 
and according to experimental studies, activation of the $\beta 2$-receptors on osteoblasts leads to production of RANKL resulting in increased osteoclastogenesis and reduced BMD. ${ }^{157}$ Bonnet et al showed that the $\beta 2$-agonists salbutamol and clenbuterol reduced bone mineral content and increased the level of bone resorption markers. Opposed to clenbuterol, however, salbutamol did not seem to have any effect on bone microarchitecture or anabolic effect on muscles. Corresponding to these results, a meta-analysis of 7 studies assessing fracture risk in patients using $\beta$-blockers concluded that their use was associated with a $28 \%$ reduction in hip fracture risk and a $14 \%$ reduction in the risk for any fracture. ${ }^{158}$

Use of convenient doses of $\beta 2$-agonists probably does not affect bone. In 2 large case-control studies increased risk of fractures associated with $\beta 2$-agonist treatment was found. ${ }^{159,160}$ Adjustments for use of OCS and disease severity, substantially reduced the excess risk found in $\beta 2$-agonist users, and causal effect of the latter seems unlikely as there was no dose dependent relation between use of inhaled short-acting $\beta 2$-agonists and fractures, in as much oral $\beta 2$-agonists were associated with an increase in fracture risk at low, but not higher doses. ${ }^{160}$

A study in rats indicated that theophylline treatment promoted skeletal calcium loss, ${ }^{161}$ and some effect on bone turnover markers were reported in a study including patients with mild asthma on theophylline treatment. ${ }^{162}$ However, no increased fracture risk by theophylline was found in a study by Vestergaard et al, ${ }^{160}$ and for anticholinergics, de Vries et al found similar risk of hip/femur fracture between users of $\beta 2$-agonists, ICS and anticholinergics, ${ }^{159}$ indicating these effects to be caused by underlying disease instead of medications. Anticholinergics and theophylline might have beneficial effects on systemic inflammation and comorbidities of COPD, but this is not proven yet. ${ }^{4}$ Interestingly, low-dose theophylline might also reverse CS resistance in COPD.

\section{Risk estimation}

Prior presence of other important risk factors enhances the adverse effects on bone by life style, COPD itself and treatment, and bone densitometry should be considered (Table 2). For patients having lost height the possibility of undiagnosed vertebral compression fractures should be considered.

Thresholds for treatment of osteoporosis previously have been at fixed T-scores given by bone densitometry. Opposed to postmenopausal osteoporosis with a recommended threshold at T-score $-2.5 \mathrm{SD}$ for initiating of treatment, the threshold in patients on CS treatment should be higher due to the
Table 2 Dual energy absorptiometry measurements recommendations

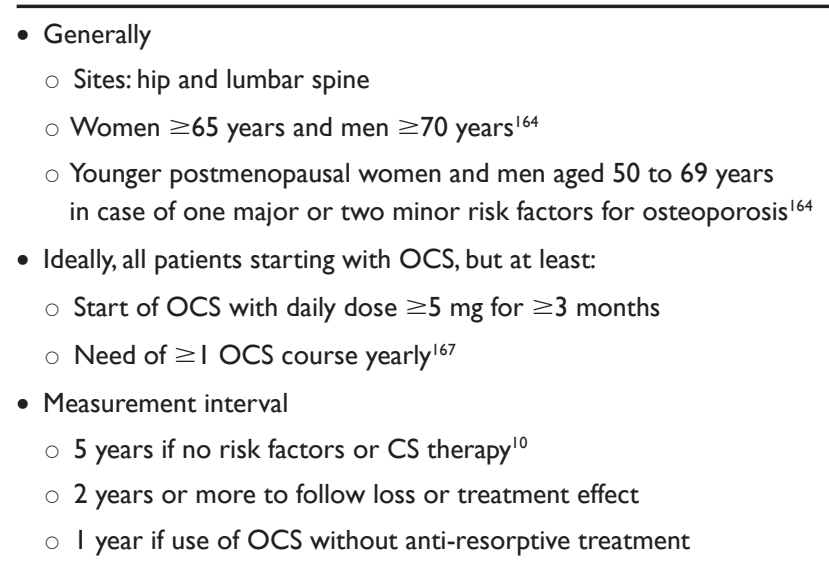

Abbreviations: CS, corticosteroids; OCS, oral corticosteroids.

adverse effect on bone not reflected by bone densitometry. The American College of Rheumatology has set cut off at -1 compared to $-1.5 \mathrm{SD}$ in the UK guidelines. ${ }^{163}$ This is supported by current evidence of CS effect on bone, and encourages more focus on estimation of absolute long-term fracture probability.

Many osteoporosis risk-assessment tools have been developed, ${ }^{164}$ and WHI Hip Fracture Risk Calculator (www. hipcalculator.fhcrc.org) and the FRAX tool (www.shef. ac.uk/FRAX), for example, could be useful supplements to BMD assessments. ${ }^{164,165}$ However, the tools are based on cohort studies, and the data might not be representative for all populations. Further, there is limited increase in risk score compared to use of BMD alone. For example, at age 50 the gradient of hip fracture risk per SD change in risk score was 2.0, 3.68 and 4.23 with use of clinical factors, BMD and both, respectively. ${ }^{166}$

\section{Recommendations for treatment of COPD patients}

Health care professionals ought to be well aware of adverse effect on bone from CS therapy, but risk evaluation is performed to a limited extent. In a US study in 2002 of osteoporosis intervention in patients on CS treatment, bone densitometry was performed in $9 \%$ of men and $27 \%$ of women exposed to OCS and in $4 \%$ of men and $23 \%$ of women exposed to ICS. ${ }^{168}$

One important aspect of COPD treatment should be to avoid bone loss and fragility fractures. This involves change in life style, treatment to allow for increased physical activity, keep CS exposure as low as possible, Calcium and vitamin D and anti-resorptive therapy (Table 3). An important challenge 
Table 3 Recommendations for prevention and treatment of osteoporosis in COPD patients

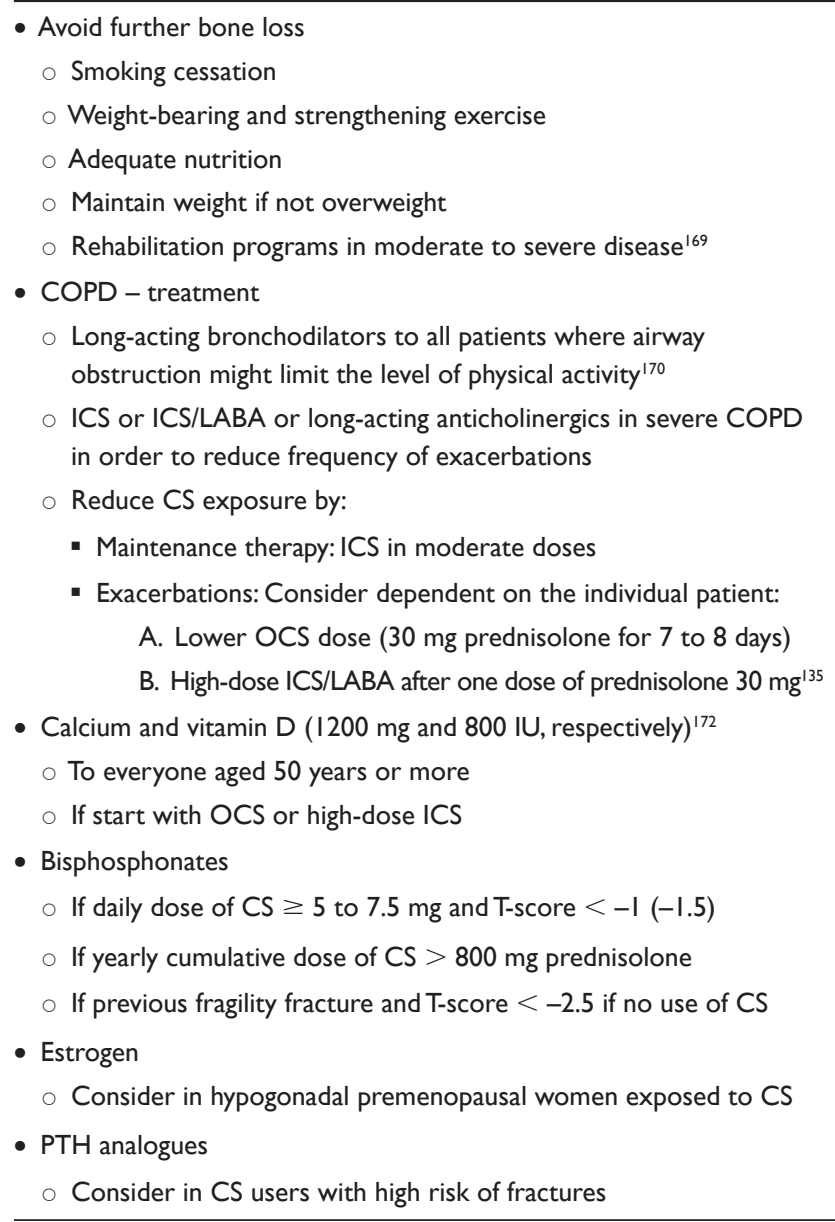

Abbreviations: CS, corticosteroids; ICS, inhaled corticosteroids; OCS, oral corticosteroids; LABA, long-acting $\beta 2$-agonist.

is to succeed in communication with all COPD patients. Especially, lower socioeconomic classes have high prevalence of COPD, but also less adherence to behavior advice.

Calcium and vitamin D supplementation reduce fracture risk, ${ }^{171}$ and early start reduced fracture risk by $12 \%$ in one study. ${ }^{172}$ Interestingly, a dose-dependent association between vitamin $\mathrm{D}$ levels and pulmonary function has been found, and vitamin D supplement might extend beyond the protective effect on bone, and influence the inflammation in the lungs and interfere with co-morbidities of COPD. ${ }^{49}$

Sex hormone treatment also reduces fracture risk. ${ }^{171}$ Estrogen preserves bone in post-menopausal women independently of CS use, ${ }^{173}$ but its use is currently limited due to concern for side effects like cardiovascular disease and breast cancer. Such treatment, however, should be considered in hypogonadal premenopausal women exposed to CS, because of limited experience with bisphosphonates beyond 10 to 12 years. ${ }^{164,174}$
Anti-resorptive therapy should be considered early during OCS treatment, as increased bone loss starts immediately after the beginning of treatment in a daily dose relationship. ${ }^{175}$ Bisphosphonates have been reported to be the most effective of evaluated agents for managing CS-induced osteoporosis, and this effect is enhanced further with concomitant use of vitamin D and calcium. ${ }^{176}$ There is strong evidence of reduced fracture risk for most of the bisphosphonates, including the intra-venous alternative zoledronic acid. ${ }^{171}$ The main effect of bisphosphonates is the inhibition of bone resorption, but they have also been shown to prevent osteoblast and osteocyte apoptosis, ${ }^{177}$ and could thereby preserve the integrity of the osteocyte network and the osteoblast lifetime.

The American College of Rheumatology recommends bisphosphonates in all men and postmenopausal women in whom long-term ( $>3$ months) CS treatment with daily dose $\geq 5 \mathrm{mg}$ is initiated, and if T-scores at the spine or hip are below -1 SD independent of OCS dose. ${ }^{174}$ The UK guidelines suggest this treatment in patients with high risk for osteoporosis; users of $\geq 7.5 \mathrm{mg}$ OCS, previous experience of a fragility fracture or other risk factors for osteoporosis. Among patients with low risk of osteoporosis, antiresorptive treatment should be considered if T-score $<-1.5$ $\mathrm{SD}$ or decline in vertebral $\mathrm{BMD} \geq 4 \%$ after 1 year of CS treatment, ${ }^{163}$ Vestergaard et al recommended fracture prevention independent of BMD status in patients reaching a yearly cumulative dose of about 800 to $900 \mathrm{mg}$ prednisolone. ${ }^{83}$ This equals 2 courses of prednisolone or a daily dose of $2.5 \mathrm{mg}$ prednisolone for 1 year.

Anabolic drugs like the parathyroid hormone analogue teriparatide stimulate bone formation through effects on osteoblasts and osteocytes, and may therefore more directly target the main pathophysiological mechanism in CS induced osteoporosis. Teriparatide has been found to be superior to alendronate in CS-induced osteoporosis, both regarding change in BMD and morphometric vertebral fractures, ${ }^{178,179}$ but there is so far weak evidence for hip fracture reduction. ${ }^{171}$ In postmenopausal women with osteoporosis, strontium ranelate also has been found to reduce fracture risk. ${ }^{180}$ The treatment has combined anabolic and anti-catabolic effect, in addition to effect on BMD due to incorporation of strontium into hydroxyapatite instead of calcium. This strengthens the correlation between increase in BMD and reduction in fracture risk, compared to other osteoporosis therapies, and might thereby increase the value of follow-up BMD as a marker of therapeutic efficacy. However, studies of the effect of strontium ranelate in CS-induced osteoporosis have not been published. ${ }^{180}$ 


\section{Conclusions}

Among available treatments for COPD, only CS-treatment has documented adverse effects of clinical significance. CS have both direct adverse effects on bone and indirect effects due to muscle weakening and atrophy. These effects are dose dependent both regarding daily dose, duration and cumulative dose. Less negative effects are seen by sporadic compared to continuous use, but lower continuous doses have less detrimental effects on bone than frequent highdose course of OCS. High doses of ICS seem to increase bone loss, but the extent of this effect is discussed because it is difficult to differentiate between the effect of ICS dose used, other risk factors, prior or concomitant use of OCS and not at least, disease severity. The health care should increase focus on healthy lifestyle and use of limited CS doses, as well as be aware of potential osteoporosis development in this group of patients. Studies on the effectiveness of use of long-acting anticholinergics or use of combinations with moderate ICS doses in severe COPD are warranted, as well as development of new anti-inflammatory drugs with specific effects on COPD inflammation and minor adverse effect on bone.

\section{Disclosures}

Dr Arnulf Langhammer is the project leader of the Lung Study in the Nord-Trøndelag Health Study (HUNT). The Lung Study was partly funded through a non-demanding grant from AstraZeneca Norway in 1995-97 (HUNT 2) and 2006-08 (HUNT 3). AstraZenca is the producer of the ICS budesonide and the long-acting $\beta 2$-agonist formoterol. $\mathrm{He}$ has also received salaries as a speaker and member of advisory boards for many different pharmaceutical companies. Additionally, in his work as general practitioner, he has participated in many multi-center studies for pharmaceutical companies. In medical practice he is joint-owner of a DXA bone densitometer.

Dr Siri Forsmo declares no conflicts of interest.

Dr Unni Syversen has received salaries as a speaker and member of several advisory boards for different pharmaceutical companies and has also participated in multicenter trials for several pharmaceutical companies.

\section{References}

1. Rabe KF, Hurd S, Anzueto A, et al. Global strategy for the diagnosis, management, and prevention of chronic obstructive pulmonary disease: GOLD executive summary. Am J Respir Crit Care Med. 2007;176(6):532-555.

2. Soriano JB, Visick GT, Muellerova H, Payvandi N, Hansell AL. Patterns of comorbidities in newly diagnosed COPD and asthma in primary care. Chest. 2005;128(4):2099-2107.
3. Decramer M, Rennard S, Troosters T, et al. COPD as a lung disease with systemic consequences - clinical impact, mechanisms, and potential for early intervention. COPD. 2008;5(4):235-256.

4. Barnes PJ, Celli BR. Systemic manifestations and comorbidities of COPD. Eur Respir J. 2009;33(5):1165-1185.

5. Schlaich C, Minne HW, Bruckner T, et al. Reduced pulmonary function in patients with spinal osteoporotic fractures. Osteoporos Int. 1998;8(3):261-267.

6. Papaioannou A, Parkinson W, Ferko N, et al. Prevalence of vertebral fractures among patients with chronic obstructive pulmonary disease in Canada. Osteoporos Int. 2003;14(11):913-917.

7. Puhan MA, Bachmann LM, Kleijnen J, ter RG, Kessels AG. Inhaled drugs to reduce exacerbations in patients with chronic obstructive pulmonary disease: a network meta-analysis. BMC Med. 2009;7:2.

8. Cummings SR, Melton LJ. Epidemiology and outcomes of osteoporotic fractures. Lancet. 2002;359(9319):1761-1767.

9. Matkovic V, Jelic T, Wardlaw GM, et al. Timing of peak bone mass in Caucasian females and its implication for the prevention of osteoporosis. Inference from a cross-sectional model. J Clin Invest. 1994;93(2):799-808.

10. Berger C, Langsetmo L, Joseph L, et al. Change in bone mineral density as a function of age in women and men and association with the use of antiresorptive agents. CMAJ. 2008;178(13):1660-1668.

11. Riggs BL, Melton LJ, Robb RA, et al. A population-based assessment of rates of bone loss at multiple skeletal sites: evidence for substantial trabecular bone loss in young adult women and men.J Bone Miner Res. 2008;23(2):205-214.

12. Holroyd C, Cooper C, Dennison E. Epidemiology of osteoporosis. Best Pract Res Clin Endocrinol Metab. 2008;22(5):671-685.

13. Dawson-Hughes B, Tosteson AN, Melton LJ, III, et al. Implications of absolute fracture risk assessment for osteoporosis practice guidelines in the USA. Osteoporos Int. 2008;19(4):449-458.

14. NIH Consensus Development Panel on Osteoporosis Prevention, Diagnosis, and Therapy. JAMA. 2001;285(6):785-795.

15. Assessment of fracture risk and its application to screening for postmenopausal osteoporosis. Report of a WHO Study Group. World Health Organ Tech Rep Ser. 1994;843:1-129.

16. Cummings SR, Bates D, Black DM. Clinical use of bone densitometry: scientific review. JAMA. 2002;288(15):1889-1897.

17. Steiger P, Cummings SR, Black DM, Spencer NE, Genant HK. Age-related decrements in bone mineral density in women over 65 . J Bone Miner Res. 1992;7(6):625-632.

18. Siris ES, Chen YT, Abbott TA, et al. Bone mineral density thresholds for pharmacological intervention to prevent fractures. Arch Intern Med. 2004;164(10):1108-1112.

19. Berger C, Langsetmo L, Joseph L, et al. Association Between Change in Bone Mineral Density (BMD) and Fragility Fracture in Women and Men. J Bone Miner Res. 2008.

20. Kanis JA. Diagnosis of osteoporosis and assessment of fracture risk. Lancet. 2002;359(9321):1929-1936.

21. Kanis JA, Gluer CC. An update on the diagnosis and assessment of osteoporosis with densitometry. Committee of Scientific Advisors, International Osteoporosis Foundation. Osteoporos Int. 2000;11(3): 192-202.

22. Orimo H, Sugioka Y, Fukunaga M, et al. The Committee of the Japanese Society for Bone and Mineral Research for Development of Diagnostic criteria of Osteoporosis: Diagnostic criteria of primary osteoporosis. J Bone Miner Metab. 1998;16:139-150.

23. Cummings SR, Black DM, Nevitt MC, et al. Bone density at various sites for prediction of hip fractures. The Study of Osteoporotic Fractures Research Group. Lancet. 1993;341(8837):72-75.

24. Marshall D, Johnell O, Wedel H. Meta-analysis of how well measures of bone mineral density predict occurrence of osteoporotic fractures. BMJ. 1996;18312(7041):1254-1259.

25. Black DM, Cummings SR, Genant HK, Nevitt MC, Palermo L, Browner W. Axial and appendicular bone density predict fractures in older women. J Bone Miner Res. 1992;7(6):633-638. 
26. Wasnich R. Bone mass measurement: prediction of risk. Am J Med. 1993;95(5A):6S-10S.

27. Gluer CC. Quantitative ultrasound techniques for the assessment of osteoporosis: expert agreement on current status. The International Quantitative Ultrasound Consensus Group. J Bone Miner Res. 1997;12(8):1280-1208.

28. Hans D, rgent-Molina P, Schott AM, et al. Ultrasonographic heel measurements to predict hip fracture in elderly women: the EPIDOS prospective study. Lancet. 1996;348(9026):511-514.

29. Vrieze A, de Greef MH, Wijkstra PJ, Wempe JB. Low bone mineral density in COPD patients related to worse lung function, low weight and decreased fat-free mass. Osteoporos Int. 2007;18(9): 1197-1202.

30. Nayak S, Olkin I, Liu H, et al. Meta-analysis: accuracy of quantitative ultrasound for identifying patients with osteoporosis. Ann Intern Med. 2006;144(11):832-841.

31. Jones A, Fay JK, Burr M, Stone M, Hood K, Roberts G. Inhaled corticosteroid effects on bone metabolism in asthma and mild chronic obstructive pulmonary disease. Cochrane Database Syst Rev. 2002;(1): CD003537.

32. Barnes PJ, Pedersen S, Busse WW. Efficacy and safety of inhaled corticosteroids. New developments. Am J Respir Crit Care Med. 1998;157(3 Pt 2):S1-S53.

33. Scanlon PD, Connett JE, Wise RA, et al. Loss of bone density with inhaled triamcinolone in Lung Health Study II. Am J Respir Crit Care Med. 2004;170(12):1302-1309.

34. Civitelli R, Rmamento-Villareal R, Napoli N. Bone turnover markers: understanding their value in clinical trials and clinical practice. Osteoporos Int. 2009;20(6):843-851.

35. Johnell O, Pauwels R, Lofdahl CG, et al. Bone mineral density in patients with chronic obstructive pulmonary disease treated with budesonide Turbuhaler. Eur Respir J. 2002;19(6):1058-1063.

36. Calverley PM, Anderson JA, Celli B, et al. Salmeterol and fluticasone propionate and survival in chronic obstructive pulmonary disease. N Engl J Med. 2007;356(8):775-789.

37. Sosa M, Jodar E, Saavedra P, et al. Postmenopausal Canarian women receiving oral glucocorticoids have an increased prevalence of vertebral fractures and low values of bone mineral density measured by quantitative computer tomography and dual X-ray absorptiometry, without significant changes in parathyroid hormone. Eur J Intern Med. 2008;19(1):51-56.

38. Minisola S, Del FR, Piemonte S, et al. Biochemical markers in glucocorticoid-induced osteoporosis. J Endocrinol Invest. 2008; 31(7 Suppl):28-32.

39. Lofthus CM, Osnes EK, Falch JA, et al. Epidemiology of hip fractures in Oslo, Norway. Bone. 2001;29(5):413-418.

40. Cauley JA, Lui LY, Ensrud KE, et al. Bone mineral density and the risk of incident nonspinal fractures in black and white women. JAMA. 2005;293(17):2102-2108.

41. Chiu GR, Araujo AB, Travison TG, Hall SA, McKinlay JB. Relative contributions of multiple determinants to bone mineral density in men. Osteoporos Int. 2009. Mar 25. [Epub ahead of print]

42. Lindsay R, Silverman SL, Cooper C, et al. Risk of new vertebral fracture in the year following a fracture. JAMA. 2001;285(3):320-323.

43. Papaioannou A, Kennedy CC, Cranney A, et al. Risk factors for low $\mathrm{BMD}$ in healthy men age 50 years or older: a systematic review. Osteoporos Int. 2009;20(4):507-518.

44. Yanbaeva DG, Dentener MA, Creutzberg EC, Wesseling G, Wouters EF. Systemic effects of smoking. Chest. 2007;131(5):1557-1566.

45. Langhammer A, Johnsen R, Gulsvik A, Holmen TL, Bjermer L. Sex differences in lung vulnerability to tobacco smoking. Eur Respir J. 2003;21(6):1017-1023.

46. Ben-Zaken CS, Pare PD, Man SF, Sin DD. The growing burden of chronic obstructive pulmonary disease and lung cancer in women: examining sex differences in cigarette smoke metabolism. Am J Respir Crit Care Med. 2007;176(2):113-120.

47. Rutherford OM. Is there a role for exercise in the prevention of osteoporotic fractures? Br J Sports Med. 1999;33(6):378-386.
48. Franco CB, Paz-Filho G, Gomes PE, et al. Chronic obstructive pulmonary disease is associated with osteoporosis and low levels of vitamin D. Osteoporos Int. 2009. Mar 20. [Epub ahead of print]

49. Janssens W, Lehouck A, Carremans C, Bouillon R, Mathieu C, Decramer M. Vitamin D Beyond Bones in COPD: Time to Act. Am J Respir Crit Care Med. 2009;179(8):630-636.

50. Hannan MT, Felson DT, wson-Hughes B, et al. Risk factors for longitudinal bone loss in elderly men and women: the Framingham Osteoporosis Study. J Bone Miner Res. 2000;15(4):710-720.

51. Zhai G, Hart DJ, Valdes AM, et al. Natural history and risk factors for bone loss in postmenopausal Caucasian women: a 15-year follow-up population-based study. Osteoporos Int. 2008;19(8):1211-1217.

52. Forsmo S, Langhammer A, Schei B. Past and current weight change and forearm bone loss in middle-aged women: the Nord-Trondelag Health Study, Norway. Menopause. 2009. May 15. [Epub ahead of print]

53. Omsland TK, Schei B, Gronskag AB, et al. Weight loss and distal forearm fractures in postmenopausal women: The Nord-Trondelag health study, Norway. Osteoporos Int. 2009. Mar 7. [Epub ahead of print]

54. Agusti A, Soriano JB. COPD as a systemic disease. COPD. 2008; 5(2):133-138

55. van Staa TP, Geusens P, Pols HA, de LC, Leufkens HG, Cooper C. A simple score for estimating the long-term risk of fracture in patients using oral glucocorticoids. QJM. 2005;98(3):191-198.

56. de Vries F, Bracke M, Leufkens HG, Lammers JW, Cooper C, van Staa TP. Fracture risk with intermittent high-dose oral glucocorticoid therapy. Arthritis Rheum. 2007;56(1):208-214.

57. van Staa TP, Leufkens HG, Abenhaim L, Zhang B, Cooper C. Use of oral corticosteroids and risk of fractures. J Bone Miner Res. 2000; 15(6):993-1000.

58. Vestergaard P, Rejnmark L, Mosekilde L. Fracture risk associated with systemic and topical corticosteroids. J Intern Med. 2005;257(4):374-384.

59. Seeman E. Osteoporosis: trials and tribulations. Am J Med. 1997;103(2 A):74S-87S.

60. Wisniewski AF, Lewis SA, Green DJ, Maslanka W, Burrell H, Tattersfield AE. Cross sectional investigation of the effects of inhaled corticosteroids on bone density and bone metabolism in patients with asthma. Thorax. 1997;52(10):853-860.

61. Sin DD, Man JP, Man SF. The risk of osteoporosis in Caucasian men and women with obstructive airways disease. Am J Med. 2003;114(1):10-14.

62. Lekamwasam S, Trivedi DP, Khaw KT. An association between respiratory function and hip bone mineral density in older men: a cross-sectional study. Osteoporos Int. 2005;16(2):204-207.

63. Eastell R. Treatment of postmenopausal osteoporosis. N Engl J Med. 1998;338(11):736-746.

64. Biskobing DM. COPD and osteoporosis. Chest. 2002;121(2):609-620.

65. Ohara T, Hirai T, Muro S, et al. Relationship between pulmonary emphysema and osteoporosis assessed by $\mathrm{CT}$ in patients with COPD. Chest. 2008;134(6):1244-1249.

66. de Vries F, van Staa TP, Bracke MS, Cooper C, Leufkens HG, Lammers JW. Severity of obstructive airway disease and risk of osteoporotic fracture. Eur Respir J. 2005;25(5):879-884.

67. Bolton CE, Ionescu AA, Shiels KM, et al. Associated loss of fat-free mass and bone mineral density in chronic obstructive pulmonary disease. Am J Respir Crit Care Med. 2004;170(12):1286-1293.

68. Katsura H, Kida K. A comparison of bone mineral density in elderly female patients with COPD and bronchial asthma. Chest. 2002;122(6):1949-1955.

69. Kjensli A, Mowinckel P, Ryg MS, Falch JA. Low bone mineral density is related to severity of chronic obstructive pulmonary disease. Bone. 2007;40(2):493-497.

70. Li L, Brennan KJ, Gaughan JP, Ciccolella DE, Kuzma AM, Criner GJ. African Americans and men with severe COPD have a high prevalence of osteoporosis. COPD. 2008;5(5):291-297.

71. Nuti R, Siviero P, Maggi S, et al. Vertebral fractures in patients with chronic obstructive pulmonary disease: the EOLO Study. Osteoporos Int. 2009;20(6):989-998. 
72. O'Neill TW, Felsenberg D, Varlow J, Cooper C, Kanis JA, Silman AJ. The prevalence of vertebral deformity in european men and women: the European Vertebral Osteoporosis Study. J Bone Miner Res. 1996;11(7):1010-1018.

73. Pauwels RA, Lofdahl CG, Laitinen LA, et al. Long-term treatment with inhaled budesonide in persons with mild chronic obstructive pulmonary disease who continue smoking. European Respiratory Society Study on Chronic Obstructive Pulmonary Disease. $N$ Engl $J$ Med. 1999;340(25):1948-1953.

74. Kjensli A, Falch JA, Ryg M, et al. High prevalence of vertebral deformities in COPD patients: relation to disease severity. Eur Respir J. 2009;33(5):1018-1024.

75. Jorgensen NR, Schwarz P, Holme I, Henriksen BM, Petersen LJ, Backer V. The prevalence of osteoporosis in patients with chronic obstructive pulmonary disease: a cross sectional study. Respir Med. 2007;101(1):177-185.

76. van Staa TP, Abenhaim L, Cooper C, Zhang B, Leufkens HG. Public health impact of adverse bone effects of oral corticosteroids. Br J Clin Pharmacol. 2001;51(6):601-607.

77. Walsh LJ, Wong CA, Oborne J, et al. Adverse effects of oral corticosteroids in relation to dose in patients with lung disease. Thorax. 2001;56(4):279-284.

78. van Staa TP, Leufkens HG, Cooper C. The epidemiology of corticosteroid-induced osteoporosis: a meta-analysis. Osteoporos Int. 2002;13(10):777-787.

79. van Staa TP. The pathogenesis, epidemiology and management of glucocorticoid-induced osteoporosis. Calcif Tissue Int. 2006; 79(3):129-137.

80. Angeli A, Guglielmi G, Dovio A, et al. High prevalence of asymptomatic vertebral fractures in post-menopausal women receiving chronic glucocorticoid therapy: a cross-sectional outpatient study. Bone. 2006;39(2):253-259.

81. Lane NE, Lukert B. The science and therapy of glucocorticoid-induced bone loss. Endocrinol Metab Clin North Am. 1998;27(2):465-483.

82. Reid IR, Evans MC, Stapleton J. Lateral spine densitometry is a more sensitive indicator of glucocorticoid-induced bone loss. J Bone Miner Res. 1992;7(10):1221-1225.

83. Vestergaard P, Rejnmark L, Mosekilde L. Fracture risk associated with different types of oral corticosteroids and effect of termination of corticosteroids on the risk of fractures. Calcif Tissue Int. 2008; 82(4):249-257.

84. de Vries F, Pouwels S, Lammers JW, et al. Use of inhaled and oral glucocorticoids, severity of inflammatory disease and risk of hip/ femur fracture: a population-based case-control study. J Intern Med. 2007;261(2):170-177.

85. Michel BA, Bloch DA, Wolfe F, Fries JF. Fractures in rheumatoid arthritis: an evaluation of associated risk factors. $J$ Rheumatol. 1993;20(10):1666-1669.

86. Ramsey-Goldman R, Dunn JE, Huang CF, et al. Frequency of fractures in women with systemic lupus erythematosus: comparison with United States population data. Arthritis Rheum. 1999;42(5):882-890.

87. Ton FN, Gunawardene SC, Lee H, Neer RM. Effects of low-dose prednisone on bone metabolism. J Bone Miner Res. 2005;20(3): 464-470.

88. van Staa TP, Laan RF, Barton IP, Cohen S, Reid DM, Cooper C. Bone density threshold and other predictors of vertebral fracture in patients receiving oral glucocorticoid therapy. Arthritis Rheum. 2003;48(11):3224-3229.

89. Steinbuch M, Youket TE, Cohen S. Oral glucocorticoid use is associated with an increased risk of fracture. Osteoporos Int. 2004;15(4):323-328.

90. Adachi JD, Ioannidis G. Calcium and vitamin D therapy in corticosteroid-induced bone loss: what is the evidence? Calcif Tissue Int. 1999;65(4):332-6.

91. Lukert BP, Raisz LG. Glucocorticoid-induced osteoporosis: pathogenesis and management. Ann Intern Med. 1990;112(5):352-364.

92. Adinoff AD, Hollister JR. Steroid-induced fractures and bone loss in patients with asthma. N Engl J Med. 1983;309(5):265-268.
93. Gluck OS, Murphy WA, Hahn TJ, Hahn B. Bone loss in adults receiving alternate day glucocorticoid therapy. A comparison with daily therapy. Arthritis Rheum. 1981;24(7):892-898.

94. Ruegsegger P, Medici TC, Anliker M. Corticosteroid-induced bone loss. A longitudinal study of alternate day therapy in patients with bronchial asthma using quantitative computed tomography. Eur J Clin Pharmacol. 1983;25(5):615-620.

95. Dubois EF, Roder E, Dekhuijzen PN, Zwinderman AE, Schweitzer DH. Dual energy X-ray absorptiometry outcomes in male COPD patients after treatment with different glucocorticoid regimens. Chest. 2002;121(5):1456-1463.

96. Matsumoto H, Ishihara K, Hasegawa T, Umeda B, Niimi A, Hino M. Effects of inhaled corticosteroid and short courses of oral corticosteroids on bone mineral density in asthmatic patients: a 4-year longitudinal study. Chest. 2001;120(5):1468-1473.

97. Manning PJ, Evans MC, Reid IR. Normal bone mineral density following cure of Cushing's syndrome. Clin Endocrinol (Oxf). 1992;36(3):229-234.

98. Laan RF, van Riel PL, van de Putte LB, van Erning LJ, van't Hof MA, Lemmens JA. Low-dose prednisone induces rapid reversible axial bone loss in patients with rheumatoid arthritis. A randomized, controlled study. Ann Intern Med. 1993;119(10):963-968.

99. Dalle CL, Bertoldo F, Valenti MT, et al. Histomorphometric analysis of glucocorticoid-induced osteoporosis. Micron. 2005;36(7-8): $645-652$.

100. Reid IR. Glucocorticoid-induced osteoporosis. Baillieres Best Pract Res Clin Endocrinol Metab. 2000;14(2):279-2198.

101. Walsh LJ, Lewis SA, Wong CA, et al. The impact of oral corticosteroid use on bone mineral density and vertebral fracture. Am J Respir Crit Care Med. 2002;166(5):691-695.

102. Kanis JA, Johansson H, Oden A, et al. A meta-analysis of prior corticosteroid use and fracture risk. J Bone Miner Res. 2004; 19(6):893-899.

103. McKenzie R, Reynolds JC, O'Fallon A, et al. Decreased bone mineral density during low dose glucocorticoid administration in a randomized, placebo controlled trial. J Rheumatol. 2000;27(9):2222-2226.

104. Baptist AP, Reddy RC. Inhaled corticosteroids for asthma: are they all the same? J Clin Pharm Ther. 2009;34(1):1-12.

105. Tattersfield AE, Harrison TW, Hubbard RB, Mortimer K. Safety of inhaled corticosteroids. Proc Am Thorac Soc. 2004;1(3):171-175.

106. Rossi GA, Cerasoli F, Cazzola M. Safety of inhaled corticosteroids: room for improvement. Pulm Pharmacol Ther. 2007;20(1): 23-35.

107. Drummond MB, Dasenbrook EC, Pitz MW, Murphy DJ, Fan E. Inhaled corticosteroids in patients with stable chronic obstructive pulmonary disease: a systematic review and meta-analysis. JAMA. 2008;300(20):2407-2416.

108. Burge PS, Calverley PM, Jones PW, Spencer S, Anderson JA, Maslen TK. Randomised, double blind, placebo controlled study of fluticasone propionate in patients with moderate to severe chronic obstructive pulmonary disease: the ISOLDE trial. $B M J$. 2000;320(7245):1297-1303.

109. Lipworth BJ. Systemic adverse effects of inhaled corticosteroid therapy: A systematic review and meta-analysis. Arch Intern Med. 1999;159(9):941-955.

110. Richy F, Bousquet J, Ehrlich GE, et al. Inhaled corticosteroids effects on bone in asthmatic and COPD patients: a quantitative systematic review. Osteoporos Int. 2003;14(3):179-190.

111. Lung Health Study Research Group. Effect of inhaled triamcinolone on the decline in pulmonary function in chronic obstructive pulmonary disease. N Engl J Med. 2000;343(26):1902-1909.

112. van Staa TP, Leufkens HG, Cooper C. Use of inhaled corticosteroids and risk of fractures. J Bone Miner Res. 2001;16(3):581-588.

113. Hubbard RB, Smith CJ, Smeeth L, Harrison TW, Tattersfield AE. Inhaled corticosteroids and hip fracture: a population-based casecontrol study. Am J Respir Crit Care Med. 2002;166(12 Pt 1): 1563-1566. 
114. Hubbard R, Tattersfield A, Smith C, West J, Smeeth L, Fletcher A. Use of inhaled corticosteroids and the risk of fracture. Chest. 2006; 130(4):1082-1088.

115. Pujades-Rodriguez M, Smith CJ, Hubbard RB. Inhaled corticosteroids and the risk of fracture in chronic obstructive pulmonary disease. QJM. 2007;100(8):509-517.

116. Langhammer A, Norjavaara E, de Verdier MG, Johnsen R, Bjermer L. Use of inhaled corticosteroids and bone mineral density in a population based study: the Nord-Trondelag Health Study (the HUNT Study). Pharmacoepidemiol Drug Saf. 2004;13(8): 569-579.

117. Langhammer A, Forsmo S, Lilleeng S, Johnsen R, Bjermer L. Effect of inhaled corticosteroids on forearm bone mineral density: the HUNT study, Norway. Respir Med. 2007;101(8):1744-1752.

118. Weatherall M, James K, Clay J, et al. Dose-response relationship for risk of non-vertebral fracture with inhaled corticosteroids. Clin Exp Allergy. 2008;38(9):1451-1458.

119. Masoli M, Weatherall M, Holt S, Beasley R. Clinical dose-response relationship of fluticasone propionate in adults with asthma. Thorax 2004;59(1):16-20.

120. Masoli M, Holt S, Weatherall M, Beasley R. Dose-response relationship of inhaled budesonide in adult asthma: a meta-analysis. Eur Respir J. 2004;23(4):552-558.

121. Barnes PJ. Immunology of asthma and chronic obstructive pulmonary disease. Nat Rev Immunol. 2008;8(3):183-192.

122. Adenuga D, Yao H, March TH, Seagrave J, Rahman I. Histone deacetylase 2 is phosphorylated, ubiquitinated, and degraded by cigarette smoke. Am J Respir Cell Mol Biol. 2009;40(4):464-473.

123. Bateman ED, Hurd SS, Barnes PJ, et al. Global strategy for asthma management and prevention: GINA executive summary. Eur Respir J. 2008;31(1):143-178.

124. Pasaoglu G, Gok H, Mungan D, Sonel B, Yalcin P, Misirligil Z. Does the combination of inhaled steroids with long acting beta2 agonists decrease the risk for osteoporosis? A 1-year prospective follow-up study. Rheumatol Int. 2006;27(2):141-146.

125. Aaron SD, Vandemheen KL, Fergusson D, et al. Tiotropium in combination with placebo, salmeterol, or fluticasone-salmeterol for treatment of chronic obstructive pulmonary disease: a randomized trial. Ann Intern Med. 2007;146(8):545-555.

126. Kardos P, Wencker M, Glaab T, Vogelmeier C. Impact of salmeterol/ fluticasone propionate versus salmeterol on exacerbations in severe chronic obstructive pulmonary disease. Am J Respir Crit Care Med. 2007;175(2):144-149.

127. Wedzicha JA, Calverley PM, Seemungal TA, Hagan G, Ansari Z, Stockley RA. The prevention of chronic obstructive pulmonary disease exacerbations by salmeterol/fluticasone propionate or tiotropium bromide. Am J Respir Crit Care Med. 2008; 177(1):19-26.

128. Zheng JP, Yang L, Wu YM, et al. The efficacy and safety of combination salmeterol (50 microg)/fluticasone propionate (500 microg) inhalation twice daily via accuhaler in Chinese patients with COPD. Chest. 2007;132(6):1756-1763.

129. Calverley PM, Boonsawat W, Cseke Z, Zhong N, Peterson S, Olsson H. Maintenance therapy with budesonide and formoterol in chronic obstructive pulmonary disease. Eur Respir J. 2003;22(6): 912-919.

130. Szafranski W, Cukier A, Ramirez A, et al. Efficacy and safety of budesonide/formoterol in the management of chronic obstructive pulmonary disease. Eur Respir J. 2003;21(1):74-81.

131. Vestbo J, Sorensen T, Lange P, Brix A, Torre P, Viskum K. Longterm effect of inhaled budesonide in mild and moderate chronic obstructive pulmonary disease: a randomised controlled trial. Lancet. 1999;353(9167):1819-1823.

132. Ferguson GT, Anzueto A, Fei R, Emmett A, Knobil K, Kalberg C. Effect of fluticasone propionate/salmeterol (250/50 microg) or salmeterol (50 microg) on COPD exacerbations. Respir Med. 2008;102(8): 1099-1108.
133. Mahler DA, Wire P, Horstman D, et al. Effectiveness of fluticasone propionate and salmeterol combination delivered via the Diskus device in the treatment of chronic obstructive pulmonary disease. Am J Respir Crit Care Med. 2002;166(8):1084-1091.

134. Hanania NA, Darken P, Horstman D, et al. The efficacy and safety of fluticasone propionate $(250 \mathrm{microg}) / \mathrm{salmeterol}$ (50 microg) combined in the Diskus inhaler for the treatment of COPD. Chest. 2003;124(3):834-843.

135. Stallberg B, Selroos O, Vogelmeier C, Andersson E, Ekstrom T, Larsson $\mathrm{K}$. Budesonide/formoterol as effective as prednisolone plus formoterol in acute exacerbations of COPD. A double-blind, randomised, noninferiority, parallel-group, multicentre study. Respir Res. 2009;10:11.

136. Manolagas SC, Jilka RL. Bone marrow, cytokines, and bone remodeling. Emerging insights into the pathophysiology of osteoporosis. $N$ Engl J Med. 1995;332(5):305-311.

137. Thornberry NA, Lazebnik Y. Caspases: enemies within. Science. 1998;281(5381):1312-1316.

138. Hofbauer LC, Khosla S, Dunstan CR, Lacey DL, Boyle WJ, Riggs BL. The roles of osteoprotegerin and osteoprotegerin ligand in the paracrine regulation of bone resorption. J Bone Miner Res. 2000;15(1):2-12.

139. Hofbauer LC, Gori F, Riggs BL, et al. Stimulation of osteoprotegerin ligand and inhibition of osteoprotegerin production by glucocorticoids in human osteoblastic lineage cells: potential paracrine mechanisms of glucocorticoid-induced osteoporosis. Endocrinology 1999;140(10):4382-4389.

140. Hardy R, Cooper MS. Bone loss in inflammatory disorders J Endocrinol. 2009;201(3):309-320.

141. Lorenzo J, Horowitz M, Choi Y. Osteoimmunology: interactions of the bone and immune system. Endocr Rev. 2008;29(4):403-440.

142. Gilbert L, He X, Farmer P, et al. Inhibition of osteoblast differentiation by tumor necrosis factor-alpha. Endocrinology. 2000; 141(11):3956-3964.

143. Cooper MS. Sensitivity of bone to glucocorticoids. Clin Sci (Lond). 2004;107(2):111-123.

144. Lovas K, Gjesdal CG, Christensen M, et al. Glucocorticoid replacement therapy and pharmacogenetics in Addison's disease: effects on bone. Eur J Endocrinol. 2009;160(6):993-1002.

145. Canalis E. Mechanisms of glucocorticoid action in bone. Curr Osteoporos Rep. 2005;3(3):98-102.

146. Yao W, Cheng Z, Busse C, Pham A, Nakamura MC, Lane NE. Glucocorticoid excess in mice results in early activation of osteoclastogenesis and adipogenesis and prolonged suppression of osteogenesis: a longitudinal study of gene expression in bone tissue from glucocorticoidtreated mice. Arthritis Rheum. 2008;58(6):1674-1686.

147. Weinstein RS, Chen JR, Powers CC, et al. Promotion of osteoclast survival and antagonism of bisphosphonate-induced osteoclast apoptosis by glucocorticoids. J Clin Invest. 2002;109(8):1041-1048.

148. Eijken M, Koedam M, van DM, Buurman CJ, Pols HA, van Leeuwen JP. The essential role of glucocorticoids for proper human osteoblast differentiation and matrix mineralization. Mol Cell Endocrinol. 2006;248(1-2):87-93.

149. Canalis E, Mazziotti G, Giustina A, Bilezikian JP. Glucocorticoidinduced osteoporosis: pathophysiology and therapy. Osteoporos Int. 2007;18(10):1319-1328

150. Lane NE, Yao W, Balooch M, et al. Glucocorticoid-treated mice have localized changes in trabecular bone material properties and osteocyte lacunar size that are not observed in placebo-treated or estrogendeficient mice. J Bone Miner Res. 2006;21(3):466-476.

151. O'Brien CA, Jia D, Plotkin LI, et al. Glucocorticoids act directly on osteoblasts and osteocytes to induce their apoptosis and reduce bone formation and strength. Endocrinology. 2004;145(4): 1835-1841.

152. Eastell R. Role of oestrogen in the regulation of bone turnover at the menarche. J Endocrinol. 2005;185(2):223-234.

153. Miller KK, Lee EE, Lawson EA, et al. Determinants of skeletal loss and recovery in anorexia nervosa. J Clin Endocrinol Metab. 2006;91(8):2931-2937. 
154. Ohnaka K, Tanabe M, Kawate H, Nawata H, Takayanagi R. Glucocorticoid suppresses the canonical Wnt signal in cultured human osteoblasts. Biochem Biophys Res Commun. 2005;329(1):177-181.

155. Hopkinson NS, Man WD, Dayer MJ, et al. Acute effect of oral steroids on muscle function in chronic obstructive pulmonary disease. Eur Respir J. 2004;24(1):137-142.

156. Bonnet N, Pierroz DD, Ferrari SL. Adrenergic control of bone remodeling and its implications for the treatment of osteoporosis. J Musculoskelet Neuronal Interact. 2008;8(2):94-104.

157. Bonnet N, Benhamou CL, Brunet-Imbault B, et al. Severe bone alterations under beta 2 agonist treatments: bone mass, microarchitecture and strength analyses in female rats. Bone. 2005;37(5): 622-633.

158. Wiens M, Etminan M, Gill SS, Takkouche B. Effects of antihypertensive drug treatments on fracture outcomes: a meta-analysis of observational studies. J Intern Med. 2006;260(4):350-362.

159. de VF, Pouwels S, Bracke M, et al. Use of beta-2 agonists and risk of hip/femur fracture: a population-based case-control study. Pharmacoepidemiol Drug Saf. 2007;16(6):612-619.

160. Vestergaard P, Rejnmark L, Mosekilde L. Fracture risk in patients with chronic lung diseases treated with bronchodilator drugs and inhaled and oral corticosteroids. Chest. 2007;132(5):1599-1607.

161. Fortenbery EJ, McDermott MT, Duncan WE. Effect of theophylline on calcium metabolism and circulating vitamin D metabolites. J Bone Miner Res. 1990;5(4):321-324.

162. Oner P, Gurdol F, Oner-Iyidon Y, Kolanci C, Buyukozturk S. Evaluation of the effect of low-dose oral theophylline therapy on some bone turnover markers and serum prolidase I activity in mild asthmatics. Pharmacol Res. 1999;40(2):189-193.

163. Compston J. US and UK guidelines for glucocorticoid-induced osteoporosis: similarities and differences. Curr Rheumatol Rep. 2004;6(1):66-69.

164. Lim LS, Hoeksema LJ, Sherin K. Screening for osteoporosis in the adult U.S. population: ACPM position statement on preventive practice. Am J Prev Med. 2009;36(4):366-375.

165. Kanis JA, Johnell O, Oden A, Johansson H, McCloskey E. FRAX and the assessment of fracture probability in men and women from the UK. Osteoporos Int. 2008;19(4):385-397.

166. Kanis JA, Oden A, Johnell O, et al. The use of clinical risk factors enhances the performance of BMD in the prediction of hip and osteoporotic fractures in men and women. Osteoporos Int. 2007;18(8): 1033-1046.

167. Shaker JL, Lukert BP. Osteoporosis associated with excess glucocorticoids. Endocrinol Metab Clin North Am. 2005;34(2):341-ix.
168. Che M, Ettinger B, Nguyen MT, Pressman AR, Johnston J. High-dose corticosteroid exposure and osteoporosis intervention in adults. Ann Allergy Asthma Immunol. 2006;97(4):497-501.

169. Lacasse Y, Brosseau L, Milne S, et al. Pulmonary rehabilitation for chronic obstructive pulmonary disease. Cochrane Database Syst Rev. 2002;(3):CD003793.

170. Cooper CB. The connection between chronic obstructive pulmonary disease symptoms and hyperinflation and its impact on exercise and function. Am J Med. 2006;119(10 Suppl 1):21-31.

171. Qaseem A, Snow V, Shekelle P, Hopkins R, Jr., Forciea MA, Owens DK. Pharmacologic treatment of low bone density or osteoporosis to prevent fractures: a clinical practice guideline from the American College of Physicians. Ann Intern Med. 2008;149(6):404-415.

172. Tang BM, Eslick GD, Nowson C, Smith C, Bensoussan A. Use of calcium or calcium in combination with vitamin $\mathrm{D}$ supplementation to prevent fractures and bone loss in people aged 50 years and older: a meta-analysis. Lancet. 2007;370(9588):657-666.

173. Gu G, Hentunen TA, Nars M, Harkonen PL, Vaananen HK. Estrogen protects primary osteocytes against glucocorticoid-induced apoptosis. Apoptosis. 2005;10(3):583-595.

174. Recommendations for the prevention and treatment of glucocorticoidinduced osteoporosis: 2001 update. American College of Rheumatology Ad Hoc Committee on Glucocorticoid-Induced Osteoporosis. Arthritis Rheum. 2001;44(7):1496-1503.

175. van Staa TP, Leufkens HG, Abenhaim L, Zhang B, Cooper C. Oral corticosteroids and fracture risk: relationship to daily and cumulative doses. Rheumatology (Oxford). 2000;39(12):1383-1389.

176. Amin S, Lavalley MP, Simms RW, Felson DT. The comparative efficacy of drug therapies used for the management of corticosteroid-induced osteoporosis: a meta-regression. J Bone Miner Res. 2002;17(8): 1512-1526.

177. Plotkin LI, Aguirre JI, Kousteni S, Manolagas SC, Bellido T. Bisphosphonates and estrogens inhibit osteocyte apoptosis via distinct molecular mechanisms downstream of extracellular signal-regulated kinase activation. J Biol Chem. 2005;280(8):7317-7325.

178. Saag KG, Shane E, Boonen S, et al. Teriparatide or alendronate in glucocorticoid-induced osteoporosis. N Engl J Med. 2007; 357(20):2028-2039.

179. Langdahl BL, Marin F, Shane E, et al. Teriparatide versus alendronate for treating glucocorticoid-induced osteoporosis: an analysis by gender and menopausal status. Osteoporos Int. 2009. Apr 7. [Epub ahead of print]

180. O’Donnell S, Cranney A, Wells GA, Adachi JD, Reginster JY. Strontium ranelate for preventing and treating postmenopausal osteoporosis. Cochrane Database Syst Rev. 2006;(4):CD005326.
International Journal of COPD

\section{Publish your work in this journal}

The International Journal of COPD is an international, peer-reviewed journal of therapeutics and pharmacology focusing on concise rapid reporting of clinical studies and reviews in COPD. Special focus is given to the pathophysiological processes underlying the disease, intervention programs, patient focused education, and self management protocols.

\section{Dovepress}

This journal is indexed on PubMed Central, MedLine and CAS. The manuscript management system is completely online and includes a very quick and fair peer-review system, which is all easy to use. Visit $\mathrm{http}: / / \mathrm{www}$. dovepress.com/testimonials.php to read real quotes from published authors. 